\title{
国土空间规划功能定位与实施分析
}

杨 玲

新疆国源测绘规划设计院有限公司，新疆 库尔勒 841000

[摘要] 国土空间规划是通过对现有的国土空间的保护和合理、充分的利用，并且从资源、要素、结构、权利等方面进行的一 项综合性、规范性、科学性的空间布局和规划，总的来说，它把各种科学合理的规划有机地结合起来，充分的实现对国土空 间的全面、系统、整体的实施、管理和监督。目前我国已形成一套较为完善的、符合我国实际情况的规划体系，但在实施的 阶段也出现了一定的问题, 集中地表现在了规划的数量很多、种类也比较繁杂、各要素之间的关系也很混乱, 各规划管理部 门各自为政等等。现行规划管理体制已不适应新时期国土空间规划发展和改革的根本要求。为进一步深化改革, 促进国土空 间规划的进一步完善和发展, 中央对政府部门进行了大刀阔斧的改革, 成立了自然资源部, 集中力量管理各类规划职能, 为 建立统一的国土空间规划体系奠定了一个坚实的基础。

[关键词] 国土空间规划; 功能定位; 实施

DOI: $10.33142 /$ aem.v3i1.3626

中图分类号: TU984.191

文献标识码: A

\section{Analysis of Function Orientation and Implementation Analysis of Land Space Planning}

YANG Ling

Xinjiang Guoyuan Surveying and Mapping Planning and Design Institute Co., Ltd., Korla, Xinjiang, 841000, China

\begin{abstract}
Land space planning is a comprehensive, normative and scientific spatial layout and planning through the protection and reasonable and full use of the existing land space and from the aspects of resources, elements, structure and rights. Generally speaking, it organically combines various scientific and reasonable planning to fully realize the comprehensive, systematic and comprehensive planning of land space overall implementation, management and supervision. At present, China has formed a relatively perfect planning system in line with the actual situation of our country, but there are also some problems in the implementation stage, which are mainly manifested in the large number of planning, the complicated types, the chaotic relationship between various elements and the different planning management departments. The current planning management system can not meet the fundamental requirements of the development and reform of land and space planning in the new era. In order to further deepen the reform and promote the further improvement and development of land and space planning, the central government has carried out drastic reform on government departments, established the ministry of natural resources, concentrated on the management of various planning functions and laid a solid foundation for the establishment of a unified land and space planning system.
\end{abstract}

Keywords: land space planning; function orientation; implementation

\section{引言}

国土空间规划作为一种规划工作的重要内容，在中国目前国土资源规划体系中占有十分重要的地位。总的来说， 国土资源的规划以土地为规划的基本要素, 土地规划主要是指由国家在其主权和主权所管辖的土地空间, 包括人类生 产、生活的载体的陆地和海洋空间等等。计划管理是经济社会发展和进步的一个重要的管理手段, 因此, 国土空间规 划在本质上也是一种管理工作。只有全面的、科学的、合理的做出国土空间的规划, 才可以进一步的优化和提升国土 空间开发保护格局, 实施国土空间用途的必要管制, 对充分的改善土地综合、高效的整治, 促进生态环境的保护与污 染修复、建设一个温馨、美丽、和谐宜居的家园等具有极为重要的意义。做好功能定位是总体规划的一个基本落脚点, 是科学的编制和实施总体规划的前提基础。所以, 要保证国土空间规划的作用, 在规划过程中对功能定位的准确把握 是关键。

\section{1 新时期国空间土规划的功能定位}

\section{1 总体定位}

土地空间规划是围绕中国土地资源的开发、保护和管理而开展的一项综合性、必要性的规划活动。这有助于充分 的协调土地资源的规划、促进社会稳定发展和生态环境的保护。总体定位是国土规划的战略和基础，其内容包括了土 
地空间的高效率的开发利用、充分的保护与必要管理等措施, 对相关活动的实施既有基础的指导作用, 又有有效的管 理控制作用。如目前已批准的《国土空间规划纲要》, 主要着重于总体发展战略、主体功能区发展战略等等。根据国土 资源的实际环境容量, 统筹推进以土地资源高效率开发、高标准保护、高效能治理为基础内容的国土空间布局规划。 可以促进我国国土开发、优化、保护等战略的实施，进而促进综合的土地总体规划的落实。

\section{2 主要功能}

中国国土规划在新时期的主要作用是进一步的促进区域功能体系的高水平的建立, 有效的确保发展过程具有较高 的科学性和约束力。科学系统的协调人口分布、土地综合利用、城市化发展布局、经济区的建设和发展, 只有确定不 同空间的主要功能定位, 并且以此为基础做好发展方向的设计, 才可以更加有效的、合理的控制国土开发的强度, 不 断调整和完善经济社会的发展结构。因而国土规划的主要职能是优化国土开发格局, 协调区域功能, 是我国的一项基 本任务 ${ }^{[1]}$ 。

\section{3 利用规划}

中国的土地利用规划与新时期以前的土地利用管理体制有着十分密切的联系。利用规划的编制是土地资源管理工 作开展的基础性的文件, 也是实行特殊用地保护的有效政策手段, 计划编制的高水平进行为中国土地高效率、科学合 理的利用和管理提供了基本遵循和依据, 逐步形成了从国家到乡镇的多层次计划编制体系。为做好重要的国土资源的 利用与保护，中国国土空间总体规划既是对我国当前国土空间规划工作的一种体现，也是一种可持续发展的保障 ${ }^{[2]}$ 。

\section{2 国土资源规划存在的问题}

\section{1 土地利用率低}

我们国家地域十分的辽阔, 土地资源和各类资源都非常的丰富, 自古以来就形成了一种简单、粗暴、不科学的管 理方式和管理体系, 对工业生产区、农业用地和居民居住区等进行随意的布局, 导致新时期发展背景下的土地规划不 合理的问题, 土地利用的水平也非常低, 造成了大量的土地资源的浪费, 这也极大地影响了中国经济社会的可持续发 展。另外, 一些地区为了吸引投资, 在短期内发展经济, 不惜代价的降低地价, 直接影响了地域的长期稳定的发展, 土地利用率存在很大的问题。

\section{2 过度开发浪费严重}

为了进一步的增加经济收入, 中国有些地区的土地存在着过度开发的问题, 为了充分的保证经济社会的稳定发展 和经济的持续增长, 不可以再盲目地、无序的使用土地, 确保那些可以直接产生经济效益的土地资源能够得到高效率 的利用, 有效的保护当地的生态环境, 避免造成土地贫㾑和国家储备的土地资源大量减少的问题, 这都有利于中国可 持续发展战略的实施。

\section{3 国土规划不合理}

现代城市的发展必须尽快的进入到新的经济发展模式上, 在上个世纪逐步建立起来的城市的老城区往往面临着十 分严重的经济发展来源的转变、经济模式的转变, 人们对于生态、自然环境的改善和生活水平、生活环境的提高有了 十分迫切的愿望, 但是受到了诸多影响因素的干扰, 我国传统的土地规划模式受到了极大的冲击。相关人员和相关部 门缺少科学的土地规划意识, 也受到了传统的粗放式发展观念的束缚, 土地规划和利用极不合理, 城市中的工业用地 过多造成了严重的环境污染, 绿地资源也严重的减少等。不合理地使用土地, 不仅会影响自然环境的保护, 而且会降 低市民居住生活的舒适度, 甚至对他们的身体健康带来严重的影响, 妨碍城市未来的发展和进步 ${ }^{[3]}$ 。

\section{3 国土空间规划实施策略}

\section{1 合理制定规划指标}

制定相关规划指标的时候必须要充分的遵循和保证国土空间规划整体开发利用以及科学保护的原则。通过高水平 的发展规划, 优化资源开发利用方式, 充分的提高资源保护利用的能力, 有效的促进生态环境的可持续、稳定健康的 发展, 根据实际情况和规划重点, 合理确定规划的各类指标, 保证规划指标的多样性、规范性、合理性, 全面的促进 国土空间规划的较高水平。注重开发安全管理, 在功能分区规划过程中全面细化整治环节, 保障规划落实 ${ }^{[4]}$ 。

\section{2 完善规划实施流程}

一是将矿产资源、水资源等重要资源的开发纳入国土空间规划体系, 统一部署, 建立健全制度, 优化补偿政策, 促进农业可持续发展; 二是加强规划部门之间的沟通与协调, 提高规划数据信息的共享与利用效率, 充分发挥监督管 
理职能, 推动国土空间规划规范化发展; 加强开发强度控制, 土地政策、投资政策和环境政策相结合, 实现良好的利 益协调; 对于大型项目开发的部署与规划, 应注重指标的层层分解与细化, 增强规划的可理解性, 并加以实施。

\section{3 重视规划实施保障和维护}

健全法规和技术标准, 明确各级政府的责任分工, 建立健全规划实施的保障体系, 从法律、制度和机制上保障规 划的实施。在促进自然资源优化配置的基础上, 建立严格的规划行政问责制和责任追究制, 建立全要素自然资源资产 核算制度, 为国土空间规划实施提供全面保障 ${ }^{[5]}$ 。

\section{4 结束语}

在新的经济社会的发展时期, 在新的社会发展和经济转型的阶段, 中国特别重视土地资源的高质量、整体化的发 展规划, 这直接决定了中国经济发展的方向和国家未来的发展方向。所以说必须要充分的关注和重视土地规划工作, 不断的增强和提高土地规划工作的水平。在土地规划工作中, 国家作为直接的决策者, 应充分发挥决策引导的作用, 制定土地规划管理的法律法规, 作为各级政府规划工作的统一标准, 保证土地规划的正确性、科学性和实用性, 使其 符合新时期国家稳定、科学、可持续发展的根本要求。

\section{[参考文献]}

[1]孙琪. 新时期国土空间规划功能定位与实施初探 [J]. 产业创新研究, 2020 (14) : 85-86.

[2]朱敏。国土空间规划功能定位与实施 [J].中国住宅设施, 2020 (4): 34-35.

[3]艾明岩. 国土空间规划功能定位与实施分析 [J]. 居舍, 2020 (6) : 1 .

[4] 张启. 新时期国土空间规划功能定位与实施的探讨 [J]. 建材与装饰, 2019 (8) : 60-61.

[5]林坚,宋萌,张安琪. 国土空间规划功能定位与实施分析 [J].中国土地,2018(1): 15-17.

作者简介: 杨玲 (1972.12-), 毕业院校: 新疆大学, 所学专业: 测绘专业, 当前就职于: 工作新疆国源测绘规划设计 院有限公司, 现任职为高级工程师、规划室主任。 